\title{
Comparison in vitro of Antioxidant Activity between Fifteen Campanula Species (Bellflower) from Palestinian Flora
}

\author{
Nidal Amin Jaradat ${ }^{1}$ and Murad Abualhasan ${ }^{* 1}$ \\ 'Department of Pharmacy, Faculty of Medicine and Health Sciences, An-Najah National University, Nablus, Palestine.
}

\begin{abstract}
Background: The natural antioxidant products in the plant kingdom play an important role in the healthy life style and reduce the risk for various chronic diseases.Objective: The objective of this study was to investigate different antioxidant pharmacological property of methanol extract for fifteen species of Campanula plant from Palestinian flora. Methods: The antioxidant activity of fifteen Campanula species growing wildly in Palestine were studied using 2,2-diphenylpicrylhydrazyl (DPPH) radical scavenging activity and their antioxidant activity was compared to Trolox antioxidant activity. Results: The results clearly demonstrate a very high antioxidant activity of the Campanula sulphurea and Campanula sidoniensis and they showed almost the same antioxidant activity of Trolox. The other twelve species extracts also exhibited excellent antioxidant activity in DPPH radical scavenging activity in comparison with trolox standard. Conclusion: Methanol extract of Campanula can be valuable for treatment of different diseases and could be used as a possible new source of natural antioxidants in the food, nutraceuticals, pharmaceuticals and cosmetic industry.
\end{abstract}

Key words: Antioxidant, Bellflower, Campanula species, Campanulaceae, DPPH radical scavenging activity.

\section{SUMMARY}

- The results show a difference in the antioxidant activity in the fifteen Campanula subgenera.

- The results clearly demonstrate a high antioxidant activity of the Campanula sulphurea and Campanula sidoniensis which show the same antioxidant activity of Trolox.
- All Campanula subgenera show a moderate antioxidant activity.

- The Campanula species could be used as a possible new source of natural antioxidants.

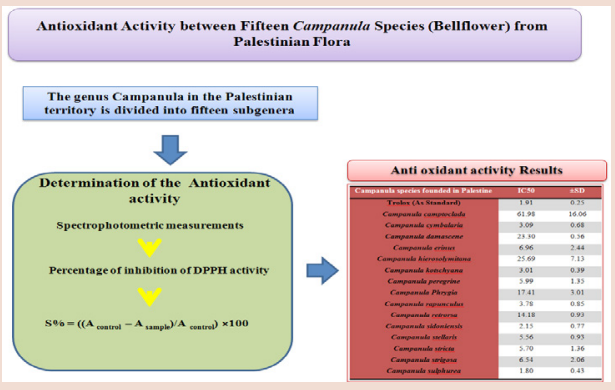

PICTORIAL ABSTRACT

Abbreviations used: DPPH, IC ${ }_{50}, U V N$ is, $S \%, A_{\text {control }}$ and $\mathrm{A}_{\text {sample }}$ Correspondence:

Murad Abualhasan, Department of Pharmacy, Faculty of Medicine and Health Sciences, An-Najah National University, Nablus, Palestine.

Email: m_abualhasan@najah.edu DOI : $10.5530 /$ pj.2015.5.4

\section{INTRODUCTION}

Palestine is unique and rich land in its natural flora diversity due to its geographical location as jointing point of Asia continent, Africa continent, and Europe continent, in addition to that it has mountains, hills, valleys, coastal plains, desert, Mediterranean Sea, Dead Sea and Rift Valley. Different climatic, phytogeographic and zoogeographic zones converges Palestine, creating great biological multi-diversity. ${ }^{1,2}$ In many developed and developing countries, a huge section of the population relies on traditional herbal healers and their armamentarium of medicinal and non medicinal plants in order to provide health care needs. ${ }^{3}$ Any therapeutic treatment or prevention of diseases began along ago with the utilization of plants, as well as the methods of preparations of folklore traditional healings throughout the world commonly used plants as part of their traditions and cultures. ${ }^{4-6}$ The plant genus Campanula L. (Bellflower) belonged to the Campanulaceae family and contains about 300 species distributed widely in temperate regions of the northern part of Hemisphere. It includes perennial or annual. This plant is widely used for several ethano-medicinal purposes by tribal peoples and traditional practitioners. $^{7}$

Most of all Campanula species grow wildly in the West and Central Asia, Black Sea, Mediterranean Sea, Eurasiatic Artic and North America regions. ${ }^{8}$ Campanula roots are fleshy and have a lot of fibers, the stems are simple, erect, stiff, slender, more or less covered with white stiff hairs, which dis- appeared when cultivated with 2 to 3 feet high. The leaves are oval or oblong and slightly crenate on long stalks, 1 to 3 inches long, the leaves on the stem are narrow, obscurely toothed or mostly entire. The flowers have purple, reddish purple, blue or white colors forming long, simple or slightly branched panicles on short peduncles which bloomed in July and August. ${ }^{9,10}$

The genus Campanula as represented in the Palestinian territory is divided into fifteen subgenera. ${ }^{11,12}$

- Campanula camptoclada Boiss.

- Campanula cymbalaria Sm.

- Campanula damascena Labill.

- Campanula erinus L.

- Campanula hierosolymitana Boiss.

- Campanula kotschyana

- Campanula peregrina L.

- Campanula phrygia Jaub. \& Spach

- Campanula rapunculus L.

- Campanula retrorsa Labill.

- Campanula sidoniensis Boiss. \& Blanche

- Campanula stellaris Boiss.

- Campanula stricta L.

- Campanula strigosa Banks \& Sol. 


\section{- Campanula sulphurea Boiss.}

Campanula plant genus contains flavonoids secondary metabolic compounds as kaempferol-3-O-glucoside, quercetin-3-O-glucoside, rutin, lobetyol, coniferin, 4'-O-(p-hydroxybenzoyl)-isorhamnetin-3,7-di-O-bD-glucopyranoside, lobetyolin, and quercetin-3-O-rutinoside and other phytochemical compounds as p-hydroxybenzoic acid, ethyl docosanoate, bis(2-ethylhexyl) adipate, sitosterolb-D-glucoside. ${ }^{13-20}$ Bellflower different species have been used as a traditional medicine in form of decoctions for treatment of various diseases such as laryngitis, constipation, warts, tonsillitis and bronchitis for a long time in addition to their use as ornamental plants, ${ }^{21,22}$ also as emetics, spasmolytic, antiallergic, antioxidant, antimicrobial, antiviral and antiphlogistic properties, as well as they possess refreshing and stimulant properties. ${ }^{23}$ The roots have been chewed fresh for treatment of lung and heart problems while the roots infusion has been used as ear drops for ears inflammations. A decoction of the entire plant has been used as a wash in the treatment of sore eyes. ${ }^{24}$

\section{METHODOLOGY}

\section{Materials and reagents}

Trolox ((S)-(-)-6-hydroxy-2, 5, 7, 8-tetramethylchroman-2-carboxylic acid) and 2, 2-Diphenyl-1-picrylhydrazyl (DPPH) were purchased from Sigma Aldrich. Methanol was of analytical grade. All other chemical reagents that are used in the research were purchased from reliable commercial sources.

\section{Instrumentation}

The following instrumentations were used: Shaker device (LabTech Shaking Incubator), rotatory evaporator (Heidolph VV2000), heater and stirrer [Heidolph OB2000], Spectrophotometer (Jenway 6505 UV/Vis Spectrophotometer).

\section{Plant material}

Campanula's fifteen species were collected from different regions in Palestine during the spring session (June- August, 2013and 2014) and authenticated by Dr. Nidal. A. Jaradat. A voucher specimen was deposited in the Herbarium of the Laboratory of Pharmacognosy at An-Najah National University as presented in (Table 1).

The plants species under study were washed twice with distilled water, dried in the shade at an average temperature of $20-30^{\circ} \mathrm{C}$, for 72 hours and stored in a dry place.

\section{Preparing of plants extracts}

For evaluating of the antioxidant capacity of studied fifteen Campanula species plants, the entire plants were powdered separately using a grinder. The extraction was performed at room temperature. About $100 \mathrm{~g}$ of the each Campanula species were soaked in 1 Liter of methanol (99\%) and put in a shaker device at 100 rounds per minute for 72 hours and stored in refrigerator for 4 days. The extracts were then filtered using filter papers. The extract was then concentrated under vacuum on a rotatory evaporator. The crude extract was stored at $4^{\circ} \mathrm{C}$ for further use, and this procedure repeated for all fifteen Campanula species.

\section{Anti oxidant activity}

\section{Trolox standard and plant working solutions}

A stock solution of a concentration of $1 \mathrm{mg} / 1 \mathrm{ml}$ in methanol was firstly prepared for all samples of plant extracts and the standard trolox. The working solutions of the following concentrations $(1,2,3,5,7,10,20,30$, $40,50,80,100 \mu \mathrm{g} / \mathrm{ml}$ ) were prepared by suitable dilution with methanol from the stock solution.
Table 1: A voucher specimen codes for all Palestinian Campanula species

\begin{tabular}{cc}
$\begin{array}{c}\text { All Campanula species founded in } \\
\text { Palestine }\end{array}$ & $\begin{array}{c}\text { Voucher specimen } \\
\text { herbarium code }\end{array}$ \\
\hline $\begin{array}{c}\text { Campanula camptoclada } \\
\text { Campanula cymbalaria } \\
\text { Campanula damascene }\end{array}$ & Pharm-PCT-476 \\
Campanula erinus & Pharm-PCT-477 \\
Campanula hierosolymitana & Pharm-PCT-478 \\
Campanula kotschyana & Pharm-PCT-479 \\
Campanula peregrine & Pharm-PCT-480 \\
Campanula Phrygia & Pharm-PCT-481 \\
Campanula rapunculus & Pharm-PCT-482 \\
Campanula retrorsa & Pharm-PCT-483 \\
Campanula sidoniensis & Pharm-PCT-484 \\
Campanula stellaris & Pharm-PCT-485 \\
Campanula stricta & Pharm-PCT-486 \\
Campanula strigosa & Pharm-PCT-487 \\
Campanula sulphurea & Pharm-PCT-488
\end{tabular}

Spectrophotometric measurements

2, 2-diphenylpicrylhydrazyl (DPPH) was freshly prepared at a concentration of $0.002 \% \mathrm{w} / \mathrm{v}$. The DPPH solution was mixed with methanol and the above prepared working concentration in a ratio of 1:1:1 respectively. The spectrophotometer was zeroed using methanol as a blank solution. The first solution of the series concentration was DPPH with methanol only.

The solutions were incubated in dark place for 30 minute at room temperature before the absorbance readings were recorded at $517 \mathrm{~nm}$.

\section{Percentage of inhibition of DPPH activity}

The percentage of antioxidant activity of the fifteen Campanula species and the Trolox standard were calculated using the following formulaThe $\mathrm{DPPH}$ radical scavenging activity (S \%) was calculated using the following equation:

$$
S \%=\left(\left(A_{\text {control }}-A_{\text {sample }}\right) / A_{\text {control }}\right) \times 100
$$

Where $\mathrm{A}_{\text {control }}$ is the absorbance of the blank control (containing all reagents except the extract solution) and $\mathrm{A}_{\text {sample }}$ is the absorbance of the test sample. The antioxidant half maximal inhibitory concentration $\left(\mathrm{IC}_{50}\right)$ for all plant samples and the standard were calculated using Bio Data Fit edition 1.2 (data fit for biologist).

\section{Data analysis}

The antioxidant activity was reported as a percentage of DPPH reduction. The inhibition of the Campanula plants and Trolox standard at different concentration were plotted and tabulated and the $\mathrm{IC}_{50}$ for each of them was calculated using the Bio Data Fit fitting program. The best fit for the data was the adapted model to calculate the $\mathrm{IC}_{50}$.

\section{RESULTS AND DISCUSSION}

\section{Antioxidant activity}

There are a lot of clinical studies suggesting that the antioxidant compounds in the plants leaves, fruits and vegetables, are the main factors for the observed efficacy of these products in reducing the incidence of chronic diseases including heart disease and some cancers. The free radical scavenging activity of antioxidants in foods has been substantially investigated and reported. ${ }^{25}$ The free radical scavenging activity of the 
Table 2: Maximum inhibitory concentration of the fifteen Campanula species and trolox standard and \pm SD

\begin{tabular}{ccc}
\hline Campanula species founded in Palestine & IC $_{50}$ & \pm SD \\
\hline Trolox (As Standard) & 1.91 & 0.25 \\
Campanula camptoclada & 61.98 & 16.06 \\
Campanula cymbalaria & 3.09 & 0.68 \\
Campanula damascene & 23.30 & 0.56 \\
Campanula erinus & 6.96 & 2.44 \\
Campanula hierosolymitana & 25.69 & 7.13 \\
Campanula kotschyana & 3.01 & 0.39 \\
Campanula peregrine & 5.99 & 1.35 \\
Campanula Phrygia & 17.41 & 3.01 \\
Campanula rapunculus & 3.78 & 0.85 \\
Campanula retrorsa & 14.18 & 0.93 \\
Campanula sidoniensis & 2.15 & 0.77 \\
Campanula stellaris & 5.56 & 0.93 \\
Campanula stricta & 5.70 & 1.36 \\
Campanula strigosa & 6.54 & 2.06 \\
Campanula sulphurea & 1.80 & 0.43 \\
\hline
\end{tabular}

methanolic extract of the entire fifteen Campanula species have been tested by DPPH radical method using Trolox as a reference standard. The concentration ranged from $1-100 \mu \mathrm{g} / \mathrm{ml}$. The zero inhibition was considered for the solution which contained only DPPH without any plant extract.

The results show a difference in the antioxidant activity for all samples. The more potent activity was for Campanula sulphurea extract was comparatively relative with $\mathrm{IC}_{50}$ of trolox standard. Moreover, the antioxidant activity for the other plants were comparative with slight difference in the antioxidant activity a summary of the antioxidant activity is presented in (Table 2).

The results clearly demonstrate a high antioxidant activity of the Campanula sulphurea and Campanula sidoniensis which show the same antioxidant activity of Trolox. Campanula cymbalaria, Campanula rapunculus have a high antioxidant activity that is equal to about half the antioxidant activity of trolox. Moreover, Campanula strigosa, Campanula stellaris Campanula peregrine Campanula erinus have an antioxidant activity that is three fold less than the Trolox antioxidant activity. All the other plants show a moderate antioxidant activity that is less than 25 $\mu \mathrm{g} / \mathrm{ml}$ with an exceptional to only one plant namely Campanula camptoclada which have an antioxidant activity of about $62 \mu \mathrm{g} / \mathrm{ml}$.

\section{CONCLUSION}

The results clearly show that the Campanula species in general have high free radical scavenging activity of antioxidants. The Campanula sulphurea in comparison with the other twelve Campanula species showed the highest antioxidant activity which was almost equal to the Trolox. Thus Campanula species could be used as a possible new source of natural antioxidants in the food, nutraceuticals, pharmaceuticals and cosmetic industry.

\section{ACKNOWLEDGEMENT}

We are thankful to the Department of Pharmacy, An-Najah University, for the technical support.

\section{CONFLICT OF INTEREST}

The authors report no conflict of interest.

\section{REFERENCES}

1. Vogiatzakis I, Mannion AM, Griffiths GH. Mediterranean ecosystems: problems and tools for conservation. Progress in Physical Geography 2006; 30(2): 175-200.

2. Eig A. On the phytogeographical subdivision of Palestine. Palestine J Bot Jer Ser. 1938; 1: 4-12.

3. Jemal A, Bray F, Center MM, Ferlay J, Ward E, Forman D. Global cancer statistics. CA: a cancer journal for clinicians 2011; 61(2): 69-90.

4. Gonzalez-Tejero M, Casares-Porcel M, Sanchez-Rojas C, Ramiro-Gutierrez J, MoleroMesa J, Pieroni A, et al. Medicinal plants in the Mediterranean area: synthesis of the results of the project Rubia. Journal of Ethnopharmacology 2008; 116(2): 341-57.

5. Schulz V. Rational phytotherapy: A reference guide for physicians and pharmacists: Springer; 2004

6. Whistler WA. Plants in Samoan Culture. the Ethnobotany of Samoa; 2000.

7. Saez L, Aldasoro JJ. A taxonomic revision of Campanula L. subgenus Sicyocodon (Feer) Damboldt and subgenus Megalocalyx Damboldt (Campanulaceae). Botanical Journal of the Linnean Society 2003; 141(2): 215-41.

8. Contandriopoulos J. Differentiation and evolution of the genus Campanula in the Mediterranean region. Plant biosystematics/edited by William F Grant; 1984.

9. Rajasekharan PO. Indigenous Ornamental Plants of Western Ghats. Underutilized and Underexploited Horticultural Crops 2007; 1(1): 77.

10. Justesen $\mathrm{H}$, Andersen AS, Brandt K. Accumulation of anthocyanins and flavones dur ing bud and flower development in Campanula isophylla Moretti. Annals of Botany 1997; 79(4): 355-60.

11. Danin A. Distribution atlas of plants in the Flora Palaestina area. Israel academy of sciences and humanities; 2004.

12. Zohary M. Flora palaestina; 1966.

13. Dumlu M, Gurkan E, Tuzlaci E. Chemical composition and antioxidant activity of Campanula alliariifolia. Natural product research 2008; 22(6): 477-82.

14. Yayli N, Yildirim N, Usta A, Ozkurt S, Akgun V. Chemical constituents of Campanula lactiflora. Turkish Journal of Chemistry 2003; 27(6): 749-56.

15. Tanaka N, Matsuura E, Terahara N, Ishimaru K. Secondary Metabolites in Transformed Root Cultures of Campanula glomerata. Journal of plant physiology 1999; 155(2): 251-4.

16. Jankovic IB, Drobac MM, Lakusic DV. Compounds of the methanolic leaf extract as chemotaxonomic markers for the Campanula pyramidalis complex (Campanulaceae). Acta Botanica Croatica 2014; 73(2): 481-90.

17. Touafek O, Kabouche Z, Brouard I, Barrera Bermejo J. Flavonoids of Campanula alata and their antioxidant activity. Chemistry of Natural Compounds 2011; 46(6): 968-70.

18. Teslov L, Koretskaya L. Flavonoids of Campanula persicifolia. I. Chemistry of Natural Compounds 1983; 19(6): 749-50. 
19. Teslov L. Luteolin triosides from Campanula persicifolia. II. Chemistry of Natural Compounds 1984; 20(6): 749-50

20. Brandt K, Kondo T, Aoki H, Goto T. Structure and biosynthesis of anthocyanins in flowers of Campanula. Phytochemistry 1993; 33(1): 209-12.

21. Roi J. Traité des plantes médicinales chinoises: Lechevalier; 1955.

22. Rameau J, Mansion D, Dumé G, Timbal J, Lecointe A, Dupont P, et al. Flore forestière française. Guide écologique illustré 1989. Tome 1: Plaines et collines. Institut pour le développement forestier; 1989. p. 1785.
23. Morton JF. Major medicinal plants: botany, culture and uses. Springfield (III: Charles C Thomas Publisher xix, 431p Illus, col illus General (KR, 198000143): 1977.

24. Pieroni A. Medicinal plants and food medicines in the folk traditions of the upper Lucca Province, Italy. Journal of Ethnopharmacology 2000; 70(3): 235-73.

25. Miller HE, Rigelhof F, Marquart L, Prakash A, Kanter M. Antioxidant content of whole grain breakfast cereals, fruits and vegetables. Journal of the American College of Nutrition 2000; 19(sup3): 312S-9S

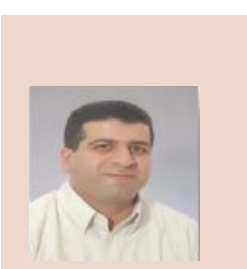

Nidal Amin Jaradat

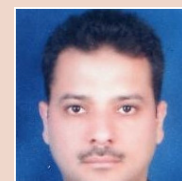

Murad Abualhasan

\section{ABOUT AUTHORS}

Dr. Nidal Amin Jaradat: Is a Ph.D holder in Pharmaceutical chemistry and Pharmacognosy. He is an Assistant professor in the department of Pharmacy at An-Najah University, Nablus Palestine. He is also the head of the Pharmaceutical chemistry and Technology Division in the pharmacy department. His research interest is in the area of pharmacosgnosy, phytochemistry and medicinal chemistry.

Dr. Murad Abualhasan: Is a PhD holder in Pharmaceutical chemistry and medicinal chemistry. He is an Assistant professor in the department of Pharmacy at An-Najah University, Nablus Palestine. His research interest is in the area of Drug synthesis, analysis, and pharmacognosy. 